\title{
KREATIVITAS FRANKY PENARI HIP HOP DI KOTA SEMARANG
}

\author{
Azrul Nur Hidayah \\ Moh. Hasan Bisri \\ Jurusan Sendratasik, Fakultas Bahasa dan Seni, \\ Universitas Negeri Semarang \\ Email: azrulnh@gmail.com
}

\begin{abstract}
SARI
Kesenian di kota Semarang sangatlah beragam khususnya pada kesenian tari yang ada. Kota Semarang memiliki seni tari tradisi atau traditional dance dan seni tari modern atau modern dance. Franky merupakan salah satu penari modern dance di Kota Semarang dan dia merupakan seorang penari Hip Hop yang mempunyai ciri khas dalam style dan konsep. Permasalahan yang dikaji dalam penelitian ini adalah bagaimana proses kreativitas Franky sebagai penari Hip Hop dan bagaimana hasil Kreativitas Franky sebagai penari Hip Hop. Tujuan penelitian ini adalah untuk mengetahui, memahami dan mendeskripsikan proses kreativitas Franky sebagai penari Hip Hop dan hasil kreativitas Franky sebagai Penari Hip Hop. Penelitian ini menggunakan metode penelitian kualitatif dengan pendekatan holistik. Teknik pengumpulan data menggunakan observasi, wawancara dan dokumentasi. Teknik keabsahan data menggunakan teknik triangulasi. Pada hasil penelitian ini dapat disimpulkan bahwa proses kreativitas Franky sebagai penari Hip Hop terdiri dari proses eksplorasi, improvisasi dan komposisi. Proses eksplorasi dilakukan untuk mengeksplor gerak-gerak dasar tari Hip Hop yang sudah ada dan memahami serta merasakan gerak khas dalam tari Hip Hop. Franky melakukan eksplorasi pada gerak-gerak dasar tari Hip Hop yaitu pada gerak Cabbage Patch dan Smurf dimana Franky dapat melakukannya dengan gerakan yang cepat. Sedangkan pada proses improvisasi, Franky mengimprovisasi gerak dasar pada tari Hip Hop yaitu pada gerak Bart Simpson. Proses komposisi merupakan gabungan dari proses eksplorasi dan proses improvisasi. Franky membuat karya tentang teknik gerak tari Hip Hop melalui karya yang berjudul "Hiphoptemporer". Hasil kreativitas Franky terdiri dari Style dan konsep. Style Franky dalam menarikan tari Hip Hop terlihat ketika Franky membawakan gerak dasar tari Hip Hop yaitu gerak Wop yang menjadi ciri khas Franky dari penari Hip Hop yang lainnya. Sedangkan konsep yang Franky miliki adalah konsep "Kill $M e$ " (bunuh aku) dimana konsep tersebut telah membawa Franky ke tingkat internasional.
\end{abstract}

Kata Kunci: Kreativitas, Penari Hip Hop 


\section{PENDAHULUAN}

Hip Hop merupakan satu dari sekian banyak jenis tarian. Hip Hop adalah sebuah gerakan budaya populer yang dimulai di Amerika Serikat pada era 1970-an. Hip Hop merupakan sebuah bentuk perlawanan dari bentuk seni masyarakat kulit putih. Dalam segala aspek kehidupan yang dilakukan masyarakat kulit putih terhadap masyarakat kulit hitam memunculkan sebuah bentuk perlawanan melalui seni, pada mulanya adalah kelahiran musik rap. Jenis nyanyian dengan ritme sangat cepat dan berbeda dari jenis musik yang menghegemoni ketika itu, yaitu jenis musik yang diproduksi dan dinyanyikan dengan harmonisasi yang diterima secara umum oleh masyarakat kulit putih. Penari Hip Hop memiliki ciri khas dalam menarikan Hip Hop. Ini yang membuat Hip Hop selalu berkreativitas.

Hip Hop merupakan satu dari sekian banyak jenis tarian, kelahirannya merupakan sebuah bentuk perlawanan dari bentuk hegemoni seni masyarakat kulit putih. Represi dalam segala aspek kehidupan yang dilakukan masyarakat kulit putih terhadap masyarakat kulit hitam memunculkan sebuah bentuk perlawanan melalui seni, pada mulanya adalah kelahiran musik rap. Jenis nyanyian dengan ritme sangat cepat dan berbeda dari jenis musik yang menghegemoni ketika itu, yaitu jenis musik yang diproduksi dan dinyanyikan dengan harmonisasi yang diterima secara umum oleh masyarakat kulit putih.
Kelahiran musik dan tarian Hip Hop yang kemudian mengalami penyebaran ke seluruh dunia, termasuk Indonesia, melalui media massa seperti film di bioskopbioskop ternama, penyanyi Hip Hop yang diorbitkan melalui perusahaan rekaman major label, dan kompetisikompetisi menari Hip Hop pada stasiun-stasiun televisi swasta. Melalui berbagai bentuk media massa yang membantu penyebaran musik dan tarian Hip Hop yang kelahirannya merupakan bentuk resistensi atas hegemoni sosial kultural, serta penyebaran Hip Hop yang didaulat oleh major label yang menciptakan sistem kapitalisme sendiri.

\section{METODE PENELITIAN}

Pada penelitian ini penulis menggunakan metode penelitian kualitatif yaitu metode penelitian yang menghasilkan data deskriptif berupa kata-kata, tulisan atau lisan dari orang orang dan perilaku yang dapat diamati (Moleong, 1998:3). Dalam hal ini data-data yang dihimpun tersebut merupakan datadata yang berkaitan dengan objek penelitian penulis. Analisis data kualitatif dilakukan secara sistematis dan serentak mulai proses pengumpulan data, mereduksi, mengklarifikasi, mendeskripsikan dan menyimpulkan serta menginterprestasikan semua informasi secara selektif (Tjetjep, 1992:10).

Pendekatan holistik berarti bahwa semua faktor diperhitungkan secara keseluruhan, saling bergantung satu sama lain untuk kepentingan semua dalam 
manajemen dan kepemimpinan hal yang berhubungan antara kepemimpinan situasional dengan motivasi, analisi transaksi, sistem kontrol, basis kuasa, kepemilikan masalah, pertumbuhan organisasi, dan perubahan (Sudjono, 2000:17).

Menurut penulis, dilihat dari permasalahan yang telah dirumuskan, penulis melakukan penelitian dengan menggunakan pendekatan holistik. Pendekatan holistik adalah sebuah cara pandang terhadap sesuatu yang dilakukan dengan konsep pengakuan bahwa hal keseluruhan adalah sebuah kesatuan yang lebih penting. Hal itu bertujuan agar metode atau teknik penelitian yang digunakan mampu memberikan arah yang jelas bagi kegiatan pengumpulan data, agar peneliti terpusat pada penemuan data yang jelas kualitasnya, dengan masalah pokok yang akan diteliti dan dianalisa guna tercapainya tujuan penelitian.

\section{HASIL PENELITIAN DAN PEMBAHASAN \\ Kreativitas}

Menurut Umar Kayam

(1981:47) kreativitas adalah proses pengungkapan yang akan melahirkan satu inovasi. Inovasi itu, karena ditemukan oleh manusia yang hidup bermasyarakat, berorientasi kepada kepentingan masyarakat.

Menurut Imam Musbikin (2006:6) kreativitas adalah kemampuan memulai ide, melihat hubungan yang baru, atau tak diduga sebelumnya, kemampuan memformulasikan konsep yang tak sekedar menghafal, menciptakan jawaban baru untuk soal-soal yang ada, dan mendapatkan pertanyaan baru yang perlu di jawab.

Menurut Supriyadi dalam Yeni

Rachmawati dan Euis Kurniati (2005:15) mengutarakan bahwa kreativitas adalah kemampuan seseorang untuk melahirkan sesuatu yang baru, baik berupa gagasan maupun karya nyata yang relatif berbeda dengan apa yang telah ada. Selanjutnya ia menambahkan bahwa kreativitas merupakan kemampuan berpikir tingkat tinggi yang mengimplikasikan terjadinya eskalasi dalam kemampuan berpikir, ditandai oleh suksesi, diskontinuitas, diverensiasi, dan integrasi antara setiap tahap perkembangan.

\section{Kreativitas Tari}

Kreativitas baik adalah aktualisasi dari pribadi yang positif. Antara lain wajib memiliki inisiatif, keberanian dan kemampuan penalaran. Menata sebuah tarian ada kalanya dimulai dari sebuah ide lalu dikembangkan dalam bentuk gerak namun dimulai dengan merangkai gerakkan lalu mencari ide, yang terpenting gerak yang dipilih wajib memiliki motivasi untuk pembentukaan tarian.

Kreativitas seseorang dapat dilihat dari hasil akhir kreatif yaitu karya. Hasil akhir itu dapat dipengaruhi oleh faktor internal dan eksternal seperti faktor lingkungan, sarana, keterampilan, identitas, orisionalitas, dan apresiasi. Teori yang diungkapkan oleh M Hawkins (2007), proses kreativitas tari dapat dilakukan dengan tahapan yaitu: eksplorasi, improvisasi dan komposisi. 
Tari

Menurut M. Jazuli dalam (Soeryobrongto: 1987, 12-34) dikemukakan bahwa gerak-gerak anggota tubuh yang selaras dengan bunyi musik adalah tari. Irama musik sebagai pengiring dapat digunakan untuk mengungkapkan maksud dan tujuan yang ingin disampaikan pencipta tari melalui penari (Jazuli, 1994:44).

Menurut Soedarsono (1972:4) menjelaskan bahwa tari sebagai ekspresi jiwa manusia melalui gerakgerak yang indah. Sedangkan menurut Hawkins (1990:2) menjelaskan tari merupakan keindahan ekspresi jiwa manusia yang diungkapkan berbentuk gerak tubuh yang diperhalus melalui estetika.

\section{Hip Hop Dance di Kota Semarang}

Tarian Hip Hop sendiri dimulai ketika Clive Campbell, alias Kool DJ Herc penemu Hip Hop datang ke New York dari Jamaika pada 1967. Ia menjadi DJ pertama yang menggunakan 2 turntable dan rekaman yang sama untuk menciptakan karyanya. Namun ia kemudian melanjutkan dengan memutus-mutus musik tersebut dan para penari yang ada ketika itu melakukan tarian dengan gerakan patah-patah yang biasa disebut breakdance.

Pada buku "Globalization and Culture" menerangkan bahwa kebudayaan suatu daerah tertentu dewasa ini menyebar dalam waktu yang terbilang singkat, hal ini difasilitasi oleh perkembangan teknologi. Perkembangan teknologi yang berperan dalam meratakan penyebaran kebudayaan ini disebut
Marx dalam Grundrisse sebagai proximity atau kedekatan, teknologi meningkatkan kedekatan jarak secara global. Jarak secara global yang ditempuh dengan cara yang lebih singkat ini merupakan sebuah hal yang disebut oleh David Harvey sebagai penyingkatan jangka waktu. Kedekatan jarak serta penyingkatan waktu ini memudahkan masyarakat di seluruh dunia untuk terhubung. Keterhubungan secara global yang menyebabkan kedekatan atau proximity merupakan sebuah konsekuensi dari modernitas global, keterhubungan secara global ini secara fenomemologi dapat dipandang sebagai sebuah keadaan dunia yang lebih padat, lebih dapat diperkirakan oleh manusia sehubungan dengan kegiatan keseharian mereka. Namun secara metaforis, kedekatan ini dapat dipandang sebagai sebuah keadaan dimana kedekatan yang meningkat ini kemudian memberikan konsekuensi lain terhadap relasi yang tidak berjarak (Tomlinson, 1999:37).

Hip Hop dance di kota Semarang mempunyai visi dan misi untuk mengembangkan entertainment khususnya di bidang dance, tidak hanya untuk komersil tetapi juga mengembangkan knowledge (pengetahuan) tentang dance itu sendiri, khususnya Hip Hop dance. Saat ini guna mewujudkan visi dan misi Hip Hop Dance di kota Semarang secara nyata sudah banyak diadakan workshopworkshop yang bermutu bahkan sampai mendatangkan dancer dari luar Indonesia. Hal ini guna mengajak teman-teman dancer untuk mempelajari segala macam gerakan tari dari masing-masing negara dan 
mencari character gerakan masingmasing.

\section{Riwayat Hidup Franky}

Franky lahir di kota Semarang pada tanggal 30 bulan Agustus tahun 1989. Franky sekarang tinggal di Jalan Kintelan Baru nomor 80, kota Semarang. Franky memiliki nama panjang Franky Dian Saputra, namun orang-orang biasa memanggilnya dengan sebutan singkat Franky. Franky juga memiliki nama panggilan khas yaitu Mr. Cupz atau Mr. Cupbe yang artinya Cup berarti piala. Franky merupakan putra kedua dari tiga bersaudara. Franky adalah putra dari pasangan bapak Soegeng Prihatin dan ibu Mujiyati.

Franky memiliki bakat sebagai penari Hip Hop diperoleh dengan tekun belajar sejak kecil, yaitu sejak Franky duduk di kelas 6 Sekolah Dasar (SD) saat Franky berusia 11 tahun dia sudah mempelajari tentang tari khususnya tari modern. Setelah Franky mempelajari tari modern lebih dalam akhirnya pada tahun 2003 tepatnya saat Franky duduk di bangku Sekolah Menengah Pertama (SMP) diusianya yang ke-14 tahun, ia mempelajari tari modern yaitu breakdance. Pada pertengahan tahun 2005 akhirnya Franky memutuskan untuk lebih dalam mempelajari Hip Hop dance dan sampai tahun 2016 sekarang ini Franky mendapat julukan Master Hip Hop yang berarti mahir dalam bidang tari Hip Hop.

\section{Unsur-Unsur Pendukung Tari Hip Hop}

Tari Hip Hop sama dengan tarian lainnya yang menggunkan unsur pendukung. Unsur pendukung itu berupa iringan, rias dan busana.
Musik pengiring yang digunakan untuk tari Hip Hop adalah musik Hip Hop instrumental maupun musik Hip Hop experimental. Dalam tari Hip Hop tidak menggunakan rias wajah yang berlebihan. Dalam tari Hip Hop menggunakan rias yang sederhana atau natural make up. Adapun kostum dalam Hip Hop dance meliputi: Topi Snapback Hip Hop, Kaos Hip Hop, Jaket Hip Hop, Sweet Pants Hip Hop dan Sepatu Sneakers Hip Hop.

\section{Dasar-Dasar Gerak Tari Hip Hop}

Dasar-dasar gerak yang terdapat dalam tari hip bop antara lain: Cabbage Patch, Prep, Wop, Bart Simpson dan Smurf.

Dasar-dasar gerak tari Hip Hop itulah yang menjadi acuan para penari Hip Hop melakukan teknikteknik gerak-gerak tari Hip Hop dengan baik dan benar.

\section{Proses Kreativitas Franky dalam Tari Hip Hop}

Franky merupakan penari Hip Hop terbaik yang sudah mumpuni dalam menarikan tari Hip Hop. Sesuai dengan teori kreativitas, Franky menerapkan dalam prosesnya yaitu:

\section{Eksplorasi}

Franky melakukan proses kreativitas, melakukan eksplor gerak dari gerak Hip Hop yang sudah ada. Franky mencoba memahami dan merasakan gerak khas dalam tari Hip Hop.

Gerak-gerak dasar dalam tari Hip Hop inilah yang dieksplor. Gerak dasar yang dieksplor adalah gerak Cabbage Patch dan gerak Smurf. Setiap penari Hip Hop mempunyai teknik gerak Cabbage 
Patch dan gerak Smurf masingmasing. Franky adalah penari Hip Hop yang terkenal akan Style dan konsepnya, namun Franky juga mempunyai ciri khas yang tersendiri saat melakukan gerak-gerak dasar Hip Hop dance, khususnya Franky mengeksplor gerak Cabbage Patch dan gerak Smurf agar terlihat tegas namun santai. Teknik yang dimiliki dapat menciptakan gerak Cabbage Patch dan gerak Smurf yang tegas dan santai.

Franky melakukan eksplorasi dalam gerak Cabbage Patch yang merupakan gerak seperti orang berlari dengan proses berfikir dan imajinasinya, ia melakukan gerakan tersebut dengan cepat dan ringan, walaupun Franky tidak melakukan gerakan Cabbage Patch di lantai datar tetapi Franky dapat membawakan gerak Cabbage Patch dengan teknik yang benar, gerak yang cepat dan lincah.

Franky melakukan eksplorasi dari gerak Smurf dengan kekuatan yang ada dibagian tangannya dan tumpuan kaki yang tepat akan membuat tubuh seimbang, sehingga keseimbangan tubuh tetap terjaga.

\section{Improvisasi}

Improvisasi dapat dilakukan setelah melakukan eksplorasi, setelah memahami dan merasakan tentang tari Hip Hop, bagaimana prinsip dasar gerak tari Hip Hop dengan itu improvisasi bisa dilakukan dengan baik. Franky melakukan improvisasi gerak tari Hip Hop berdasarkan gerak-gerak dasar yang ada dan dipadukan dengan gerak cepat dan teknik yang dimiliki.

Franky mengimprovisasi gerak Bart Simpson saat ia melakukan gerak tersebut di tangga. Di tangga tersebut terlihat sangat terbatas untuk ruang gerak Franky saat melakukan gerak Bart Simpson dengan levellevel yaitu level tinggi, level sedang dan level rendah, namun ia membawakan gerakan Bart Simpson tersebut dengan lihai.

Pada gerakan Bart Simpson menggunakan teknik melompat kecil yang sebenarnya di lakukan di lantai datar, Franky melakukannya di tangga yang sebenarnya ada banyak resiko jika melakukan gerakan tersebut dengan kondisi lantai yang tidak dasar dapat mempengaruhi gerak dan kecelakaan yang dapat terjadi, misalnya: terpeleset, jatuh maupun terkilir. Namun Franky membawakan gerak Bart Simpson tersebut dengan tegas, mudah dan tanpa cidera walaupun dilakukan di ruang gerak yang terbatas seperti di atas tangga tersebut.

\section{Komposisi}

Eksplorasi dan improvisasi berhasil dilakukan, tahap terakhir adalah komposisi, yaitu tahap yang menggabungkan eksplorasi dan improvisasi. Tahap ini diperlukan totalitas dalam pembuatan karya, Franky menuangkan karya tentang teknik gerak tari Hip Hop "Hiphoptemporer".

"Hiphoptemporer" merupakan karya tari yang khusus di dalamnya terdapat gerak-gerak dasar tari Hip Hop. Sehingga, jika ada pemula yang sedang melakukan pembelajaran tari Hip Hop dapat mempelajari karya tersebut. Dengan karya tersebut Franky berani mempertangung jawabkan atas kebenaran seluruh gerak-gerak dasar yang ada dalam tari Hip Hop. 


\section{Hasil Kreativitas Franky Sebagai Penari Hip Hop}

Franky adalah penari Hip Hop yang dikenal mempunyai kreativitas dalam Style dan konsep yang ia miliki. Postur tubuh Franky yang tinggi dan ramping membuat badannya dapat digerakkan secara ringan dan cepat.

\section{Style (gaya)}

Style Franky dalam menarikan tari Hip Hop sangatlah mengagumkan. Franky memiliki Style yang unik dan berbeda dari penari-penari Hip Hop yang lainnya.

Style yang Franky milik ini, menjadi ciri khasnya. Franky memiliki Style yang berbeda saat ia melakukan gerakan Wop terlihat dalam pengambilan rekaman video. Gerakan dasar Hip Hop dance yaitu gerakan Wop yang biasanya dibawakan oleh penari-penari Hip Hop dalam hitungan 1 detik dapat melakukan gerakan Wop sebanyak satu kali, namun dalam waktu 1 detik tersebut Franky dapat melakukan gerakan Wop sebanyak dua sampai tiga kali bahkan lebih sesuai dengan iringan musik. Kecepatan tangan Franky itulah yang buat gerakan Wop Franky berbeda dengan gerakan Wop penari Hip Hop yang lainnya. Di samping itu dengan gerakan Wop tersebut Franky melakukannya menggunakan bounce atau gerakan memantul pada bagian tubuh yaitu bagian dada yang mengikuti harmony (keselarasan) gerak Wop tersebut. Sehingga gerakan Wop yang cepat bagi penari Hip Hop yang lainnya bisa Franky bawakan secara ringan dan santai. Karena kunci dari gerakan Wop itu sendiri terletak pada kekuatan tangan, membutuhkan latihan fisik terutama pada bagian tangan agar tangan tidak lemas saat melakukan gerakan Wop. Latihan fisik pada tangan itulah yang dapat membuat tangan menjadi kuat kuat namun ringan untuk digerakan, sehingga dapat mengunci gerakangerakan Wop dan dapat menguasai teknik gerak tangan pada gerakan Wop dengan benar. Gerakan ini selalu Franky gunakan saat menarikan tari Hip Hop pada bagian awal penyajian. Gayanya yang begitu santai namun tegas membuktikan bahwa Franky melakukan gerakan ini dengan baik.

\section{Konsep}

Franky memiliki banyak
konsep yang ada di dalam pemikirannya. Konsep tersebut yang membuat tari Hip Hop Franky berbeda dengan yang lain. konsep yang Franky miliki dan yang selalu Franky ciptakan memiliki alur cerita dan alur cerita tersebut di sampaikan Franky melalui gerak tari Hip Hop yang ia tarikan. Sehingga dengan gerakan yang Franky bawakan setiap orang memahami apa yang sedang Franky lakukan dan Franky sampaikan melalui gerak-gerak tari tersebut. Itu yang membuat Franky selalu memiliki keunggulan dalam menarikan tari Hip Hop dengan konsep yang indah yang membuat orang-orang yang melihatnya ingin mengetahui apa makna yang terkandung dalam tarian Hip Hop yang sedang Franky bawakan.

\section{SIMPULAN}

Proses kreativitas Franky sebagai penari Hip Hop terdiri dari proses eksplorasi, improvisasi dan komposisi. Proses eksplorasi 
dilakukan untuk mengeksplor gerak tari Hip Hop yang sudah ada dan memahami serta merasakan gerak khas dalam tari Hip Hop. Pengeksploran gerak tersebut dilakukan oleh Franky pada gerak Cabbage Patch dan Smurf. Pada gerak dasar tari Hip Hop yaitu gerakan Cabbage Patch dan Smurf Franky melakukan dengan menyeimbangkan anggota tubuh sehingga gerakan tersebut dapat dibawakan dengan ringan namun terlihat tegas. Sedangkan pada proses improvisasi, Franky memadukan gerak dasar dan gerak-gerak cepat dengan teknik yang dimilikinya melalui gerak dasar Hip Hop dance yaitu pada gerak Bart Simpson. Pada gerakan Bart Simpson Franky mengunakan improisasi menggunakan level-level yaitu level rendah, level sedang dan level tinggi. Gerakan Bart Simpson Franky improvisasi menggunkan level-level karena belum tentu semua penari Hip Hop melakukan gerakan Bart Simpson mengunakan level-level yang pada gerakan dasar Bart Simpson hanya menggunakan level tinggi. Proses komposisi merupakan gabungan eksplorasi dan improvisasi yang Franky lakukan dengan membuat karya tentang teknik gerak dasar Hip Hop dance melalui karyanya yang berjudul "Hiphoptemporer".

Hasil kreativitas Franky terdiri dari ciri khas Style (gaya) dan konsep yang Franky miliki. Ciri khas Style Franky yang berbeda tersebut ia bawakan melalui gerak dasar Hip Hop dance yaitu pada gerakan Wop. Sedangkan konsep "Kill Me" yang dimiliki Franky selalu memiliki alur cerita untuk menarik para penonton untuk mempelajari tentang makna tarian yang sedang Franky bawakan. Sehingga tari Hip Hop yang ia bawakan bukan hanya sekedar sebuah tontonan tari Hip Hop, namun tari Hip Hop yang berbeda dengan tari-tari Hip Hop yang lainnya. Konsep yang Franky bawakan selalu tersirat makna yang dapat memotivasi untuk setiap penoton atau penggemarnya.

\section{SARAN}

Saran yang diberikan kepada Franky adalah agar Franky tetap mempertahankan kreativitas yang dimilikinya terutama dalam style (gaya) dan konsep. Sehingga kreativitas tersebut menjadi ciri khas Franky dalam menarikan tari Hip Hop.

Pengembangan ide-ide yang dimiliki oleh Franky diharapkan dapat menjadikan Franky lebih maju, sehingga Franky dapat terus meningkatkan kreativitasnya baik untuk dirinya sendiri maupun ilmu yang ia miliki dapat ia berikan kepada orang lain untuk belajar mengenai Hip Hop dance.

\section{DAFTAR PUSTAKA}

Hawkins. 2007. Consumer Behavior: Building Marketing Strategy. New York: McGraw Hill Company Inc

Imam Musbikin. 2006. Mendidik Anak Kreatif ala Einstein. Yogyakarta: Mitra Pustaka

Jazuli, Muhammad. 1994. Telaah Teorotis Seni Tari. Semarang: IKIP Semarang Press 
Kayam, Umar. 1981. Seni, Tradisi, Masyarakat. Jakarta: Sinar Harapan

Lexy J, Moleong. 1998. Metode Penelitian Kualitatif. Bandung: Rosdakarya

Soedarsono. 1972. Djawa dan Bali. Yogyakarta: Gadjah Mada University Press

Ratih E.W., E. (2011). FUNGSI TARI SEBAGAI SENI PERTUNJUKAN (The Function of Dance as A Performing Art). Harmonia: Journal Of Arts Research And Education, 2(2). doi:http://dx.doi.org/10.15294/ harmonia.v2i 2.854

Malarsih, M. (2016). The Tryout of Dance Teaching Media in Public School in The Context of Appreciation and Creation Learning. Harmonia: Journal Of Arts Research And Education, 16(1), 95-102. doi:http://dx.doi.org/10.15294/ harmonia.v16i1.4561

Tomlinson, John. 1999.

Globalization and Culture.

Chicago: The University of Chicago Press.

Purnaningtyas, A., \& Suharto, S. (2011). PENGARUH KECERDASAN EMOSI TERHADAP PRESTASI BELAJAR SISWA MATA PELAJARAN SENI BUDAYA SMP. Harmonia: Journal Of Arts Research And Education, 10(1). doi:http://dx.doi.org/10.15294/ harmonia.v10i1.56

Yeni Rahmawati, Euis Kurniati. 2005. Strategi Pengembangan Kreativitas pada Anak. Jakarta: Depdiknas 